\title{
NORADRENALINE AS A VASOCONSTRICTOR IN LOCAL ANAESTHESIA FOR THORACOPLASTY BY
}

\author{
H. E. BELL \\ From the Newcastle Regional Surgical Unit
}

(RECEIVED FOR PUBLICATION OCTOBER 18, 1954)

One of the chief advantages of local anaesthesia in thoracoplasty operations is the small amount of blood lost that accompanies its use, and in the Newcastle Regional Thoracic Surgery Unit (Seaham Hall Hospital) local anaesthesia remains the anaesthetic of choice for the standard two-stage operation. The haemostasis associated with local infiltration anaesthesia is directly due to the added vasoconstrictor drug. Adrenaline, introduced by Braun in 1900, still holds pride of place for this purpose.

During thoracoplasty operations much of the blood is lost during section of the thick muscular layer. In the hope of minimizing this loss it was decided to investigate the effect of noradrenaline in place of adrenaline, for physiologically noradrenaline is a constrictor of muscle vessels while adrenaline is actually a dilator (Barcroft and Swan, 1953). (From intra-arterial infusion experiments, however, adrenaline in high concentration has been shown to cause vasoconstriction in skeletal muscle and this presumably explains any haemostatic effect it has in local anaesthesia (Barcroft and Swan, 1953) ). In view of the sole vasoconstrictor action of noradrenaline it was felt reasonable to try its effect in place of adrenaline.

Over 50 first-stage thoracoplasty operations have now been completed using noradrenaline thus, and the resulting diminution in blood loss would appear to merit its continued use. The standard local anaesthetic technique for these operations is used, with the substitution of noradrenaline for adrenaline in the solution for infiltrating the muscle layer. A concentration of 1 in 125,000 has been found satisfactory, and in the average case $75 \mathrm{ml}$. of this solution is used $(0.6 \mathrm{mg}$. noradrenaline base). For the nerve block (brachial plexus and paravertebral) and skin infiltration the use of adrenaline in a concentration of 1 in 400,000 has been continued unaltered, and normally 0.4 mg. adrenaline is used. Noradrenaline is quite inferior to adrenaline as a constrictor of skin vessels, hence nothing is to be gained from its use here (Mayer and Ruben, 1952).

The improved haemostasis is seen typically as (1) decreased oozing and (2) sluggish bleeding from distinct points. Spouting vessels are not $\stackrel{2}{\overrightarrow{2}}$ often seen and bleeding points are easily clipped off. The actual number of points does not seem to be appreciably diminished. The net result is? thus an obvious reduction in blood loss, a point $\stackrel{\infty}{N}$ of considerable importance in as extensive an 을 operation as thoracoplasty, and a saving in operation time. In an occasional case, however, $\subset$ possibly from technical reasons, the haemostasis was not quite so satisfactory. No attempt was $\vec{\oplus}$ made to measure blood loss, as, owing to the many variable factors such as size, age, sex, muscular development, blood pressure, etc., a very large number of cases would have been necessary to make the results statistically acceptable. The recording of this technique was felt to be justified because of its usefulness in minimizing blood $\stackrel{\mathbb{Q}}{\mathscr{Q}}$ loss and in reducing operation time.

The effect on the blood pressure was noted care- $\frac{3}{3}$ fully. In general there is a slightly greater rise than when adrenaline alone is used, but it was? satisfactory to note that this rise was not as great as might have been anticipated considering the으 amount of noradrenaline used. In the average $x$ case with a pre-operative blood pressure of $120 / \%$ $75 \mathrm{~mm} . \mathrm{Hg}$ a peak rise to $135 / 85 \mathrm{~mm}$. Hg may be expected 15 to 20 minutes after finishing the localo anaesthetic procedure. In no case was there any alarming rise and in some there was no rise at allo from the pre-operative reading. There is a ten- $\rightarrow$ dency to a more abrupt fall in blood pressure in the later stages of the operation than where adrenaline alone is used. In the few cases in which the blood pressure fell in this way it was 0 of a temporary nature, and when it occurred the patient sometimes complained of nausea. There were no cases of haemorrhage from the woundo following operation and healing was unaffected.

I wish to express my thanks to Mr. S. G. Griffin. F.R.C.S., for his co-operation, and also to Messrs. Bayer Products, Ltd., for their assistance.

\section{REFERENCES}

Barcroft, H., and Swan, H. J. C. (1953). Sympathetic Control of Human Blood Vessels (Monogr. Physiol. Soc., No. 1), Arnold London.

Mayer, R. A., and Ruben, J. E. (1952). J. Philad. gen. Hosp, 3, 18 . 